\title{
Experimental Investigation of Refractive Index Measurement of Common Solvents and Aqueous Solutions in the Infrared Wavelengths
}

\author{
C. İde, K. Yüksel
}

\begin{abstract}
We proposed and experimentally demonstrated a fast and simple technique to measure refractive index of liquids. A commercial Optical Time-Domain Reflectometer (OTDR) was implemented for interrogating sensor tips from a remote location. The system uses Fresnel reflected light from standard single mode fiber tips as sensing points without requiring any chemical coating, delicate fiber components, and/or sophisticated architecture at the sensor head. We reported new measurements of refractive indices of common solvents and solutions at both $1550 \mathrm{~nm}$ and $1625 \mathrm{~nm}$. The precision of the proposed measurement system was found to be in the order of $10^{-4}$. The experimental results have been validated by the way of theoretical calculations.
\end{abstract}

Index Terms-Fiber optic refractometer, Fresnel reflection, OTDR, refractive index measurement.

\section{INTRODUCTION}

$\mathrm{R}$ EFRACTIVE INDEX measurement is frequently used in a variety of fields, such as chemical industry, food quality and safety analysis, bio-medical applications, environmental imaging systems, petroleum and oil industry and material processing [1]. Being a very critical parameter in all of these areas, there is an increasing interest, in recent years, in determining the exact value of the refractive index of the materials. Several research groups have published different types of fiber-based refractive index sensors which include fiber Bragg gratings (FBG) structures, long period gratings (LPGs) structures, interferometers, photonic crystal fibers (PCF) and sensors using Surface Plasmon Resonance (SPR) effects $[2,3]$.

Among these various sensor approaches, Fresnel reflectionbased refractometers have emerged as promising tool for refractive index monitoring due to their simplicity and easy accessibility. In Fresnel-reflection-based refractometers, interrogation can be done in various ways. Table I summarizes the interrogation methods, sensitivities and precisions of different Fresnel-reflection-based fiber optic refractometers reported in the literature.

C. İDE, is with Department of Electrical-Electronics Engineering University of Izmir Institute of Technology, Izmir, Turkey, (e-mail: cansuide@iyte.edu.tr)

K. YÜKSEL, is with Department of Electrical-Electronics Engineering University of Izmir Institute of Technology, Izmir, Turkey, (e-mail: kivilcimyuksel@iyte.edu.tr)

Manuscript received May 30, 2018; accepted June 16, 2018.

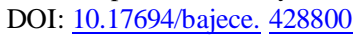

In the literature, for the methods based on conventional single-wavelength OTDR scheme, the separation of different sensor points is limited by the OTDR's dead zone. Hence, the multi-point measurement capability remains as a critical issue. This problem was addressed by our previous work [4] presenting a limited number of proof-of-concept measurements. Thanks to this approach, where a multiwavelength OTDR is used for measuring the modified optical power of the light reflected from the sensing probes, the spatial resolution of OTDR does not limit the distances between sensors point.

In the present work, we elaborated our previously proposed method taking into account all the practical parameters such as real concentration values of the solutions as well as the effective refractive indices of the sensor tips at the measurement wavelength range. We investigated the refractive indices of common solvents, glycerin-water, and alcoholwater solutions in the infrared wavelength region (used in fiber-optic telecommunications). Moreover, our proposed method was extensively supported by a considerable amount of measurements including long-term repeatability tests. Comparison of the experimental results with that of theoretical calculations presented a good agreement. This shows a great potential of the system in a wide panel of applications requiring the self-calibration and easy implementation features, particularly those in difficult environments.

\section{SENSING PRINCIPLE OF FRESNEL REFLECTION-BASED REFRACTIVE INDEX SENSOR}

The operation principle of the proposed sensor was based on the measurement of Fresnel-reflection coefficient at the interface between the optical fiber and the sample. In this sensor, conventional single mode fiber tips were used as sensing points and a multi-wavelength OTDR was used as interrogation unit.

At the fiber end (flat cleaved fiber end) where the index of refraction differs, a small portion of the incident light is reflected back into the fiber. Power reflection coefficient $R$ of this Fresnel reflected light can be quantified by the following expression at the interface between fiber end and air:

$$
R=\left(\frac{n_{1}-n_{2}}{n_{1}+n_{2}}\right)^{2}
$$


Where $n_{1}$ is the effective refractive index of the fiber, and $n_{2}$ is the refractive index of the second medium which is air in this case $\left(\mathrm{n}_{2}=\mathrm{n}_{\mathrm{air}}=1.0002739\right)$ [5]. Power reflection coefficient can be measured by using an optical time domain reflectometer (OTDR) as represented in Fig. 1.

TABLE I

SUMMARY OF THE FRESNEL REFLECTION-BASED REFRACTOMETERS

\begin{tabular}{|c|c|c|c|c|}
\hline \begin{tabular}{|c|} 
Source \\
\end{tabular} & Interrogator & Sensitivity & Precision & Ref. \\
\hline $\begin{array}{c}\text { Diode laser } \\
\text { (modulated by a pulse train) }\end{array}$ & $\begin{array}{l}\text { Photodetector and } \\
\text { computer }\end{array}$ & 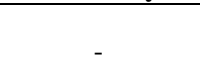 & $2.5 \times 10^{-5}$ & [6] \\
\hline $\begin{array}{c}\text { Diode laser } \\
\text { (modulated by a pulse train) }\end{array}$ & $\begin{array}{c}\text { Photodetector and digital } \\
\text { oscilloscope }\end{array}$ & - & $\begin{array}{l}\text { Short-time: } 2.8 \times 10^{-6} \\
\text { Long time: } 2.9 \times 10^{-5}\end{array}$ & [7] \\
\hline $\begin{array}{c}\text { Broadband Source } \\
(\text { centered at } 1550 \mathrm{~nm})\end{array}$ & Photodetector & - & $\begin{array}{l}\text { Short-time: } 8 \times 10^{-6} \\
\text { Long-time: } 5 \times 10^{-5}\end{array}$ & [8] \\
\hline Laser diode (at $635 \mathrm{~nm}$ ) & Photodetector & - & $10^{-4}$ & {$[10]$} \\
\hline OTDR's light source & $\begin{array}{c}\text { Commercial OTDR } \\
(1550 \mathrm{~nm}) \\
\end{array}$ & $\begin{array}{c}38.70 \mathrm{~dB} / \mathrm{RIU} \text { to } \\
304.73 \mathrm{~dB} / \mathrm{RIU} \\
\end{array}$ & Long-time: $2.9 \times 10^{-5}$ & {$[11,12]$} \\
\hline OTDR's light source & $\begin{array}{c}\text { Multi-wavelength OTDR } \\
\text { and AWG }(1550 \mathrm{~nm} \text { and } \\
1625 \mathrm{~nm})\end{array}$ & - & $4.7 \times 10^{-4}$ & $\begin{array}{l}\text { This } \\
\text { work }\end{array}$ \\
\hline
\end{tabular}

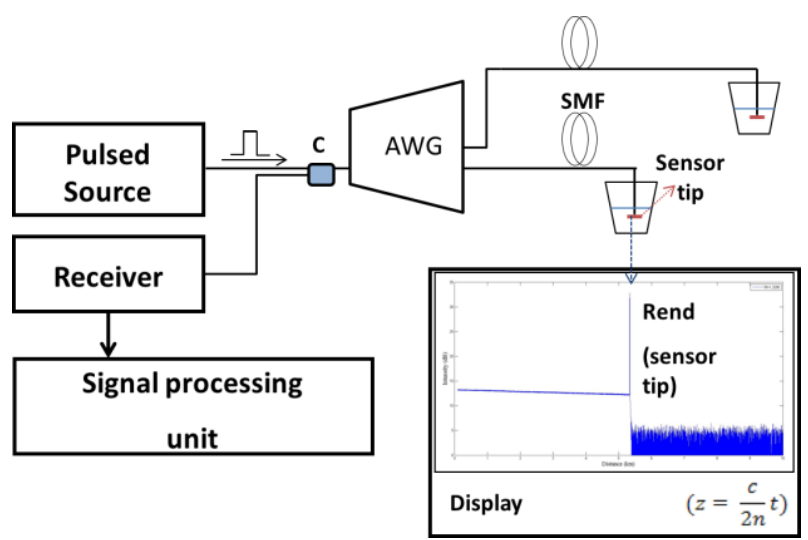

Fig.1. Refractive index measurement using OTDR. AWG: Array Waveguide Grating

The amount of reflected light can be calculated by the differences in the refractive index of the two fibers joined, or any sample (air or chemical) at the end of the fiber. When the fiber tip is immersed into the liquid sample as shown in Fig. 1, the RI value of the liquid can be determined by measuring the end reflection peak ( $R_{\text {end }}$ ):

$$
\begin{array}{ll}
n_{2}=n_{1} \frac{\left[1-10^{R_{\text {end }} / 20}\right]}{\left[1+10^{R_{\text {end }} / 20}\right]}, & n_{1}>n_{2} \\
n_{2}=n_{1} \frac{\left[1+10^{R_{\text {end }} / 20}\right]}{\left[1-10^{R_{\text {end }} / 20}\right]}, & n_{1}<n_{2}
\end{array}
$$

The effective refractive index of the fundamental mode $\left(\mathrm{n}_{1}\right.$ or $\mathrm{n}_{\text {eff) }}$ was obtained as $\mathrm{n}_{1}=1.4473$ at $1550 \mathrm{~nm}$, and $\mathrm{n}_{1}=$ 1.4463 at $1625 \mathrm{~nm}$. In the case of each wavelength $(1550 \mathrm{~nm}$, $1625 \mathrm{~nm}$ ) the very well-known Sellmeier equation given in (4) was implemented for the sensor fiber $\left(4.5 \% \mathrm{GeO}_{2}\right.$ doped silica fiber) $[6,13,14]$.

$$
n^{2}=1+\sum_{i=1}^{3} \frac{A_{i} \lambda^{2}}{\lambda^{2}-B_{i}^{2}}
$$

\section{EXPERIMENTS}

The glycerin-pure water solutions having different concentration levels were used to obtain the calibration characteristics of the Fresnel-based refractive index sensor. Reference measurements were realized with a conventional refractometer (model: RE50 digital refractometer). Fig. 2 represents the relation between the concentration values and the corresponding refractive indices of the glycerin-distilled water measured by the RE50 digital refractometer. Refractometer's light source emits at $589.3 \mathrm{~nm}$.

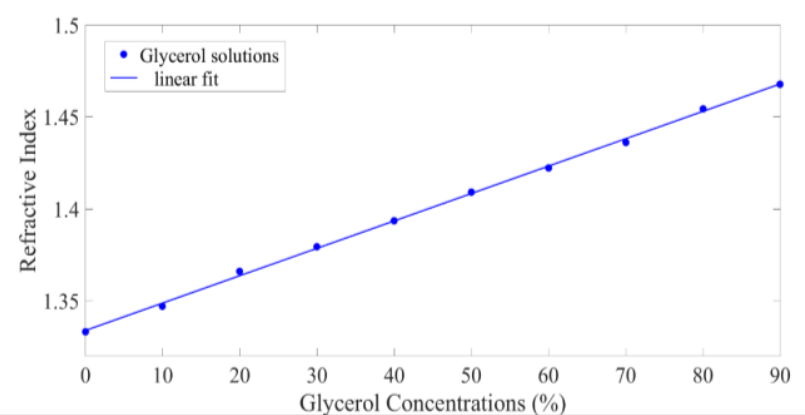

Fig.2. Measured refractive indices of the glycerin-distilled water solutions

The fitting function of Fig. 2 is $\mathrm{n}=0.0014904 \times \mathrm{C}+1.3337$, having a fitting degree of $\mathrm{R}^{2}=0.9999$.

In the experiments, two fiber tips were simultaneously used as sensing points. The optical pulses sent by the interrogation unit (Multi-wavelength OTDR) at two wavelengths (1550 nm and $1625 \mathrm{~nm}$ ) were separated by a WDM coupler. The fiber tips were standard single mode fibers without the jacket (cut perpendicularly to the fiber axis by using a cleaver).

OTDR parameters set during the measurements are listed in Table II. 
TABLE II OTDR PARAMETERS

\begin{tabular}{c|c} 
Parameter & Value \\
\hline Distance range & $10 \mathrm{~km}$ \\
Averaging time & $15 \mathrm{secs}$ \\
Pulse width & $5 \mathrm{~ns}$
\end{tabular}

The experiments were realized in two sections:

- SET-1: The sensor tip at $1550 \mathrm{~nm}$ was immersed in glycerin solutions prepared at different concentrations, while a second sensor tip at $1625 \mathrm{~nm}$ was kept in pure water.

- SET-2: The sensor tip at $1625 \mathrm{~nm}$ was immersed in glycerin solutions prepared at different concentrations, while a second sensor tip at $1550 \mathrm{~nm}$ was kept in pure water.

In both cases, the reflection coefficients from sensor tips were measured on the OTDR display. As an example, the change of end reflection peak for three different glycerol concentration values $(20 \%, 30 \%$, and $40 \%)$ is shown in Fig. 3.

Once the calibration characteristics had been obtained for both sensor tips, additional experiments were realized to measure the refractive indices of some chemicals such as acetone, isopropyl alcohol, methanol and ethanol.

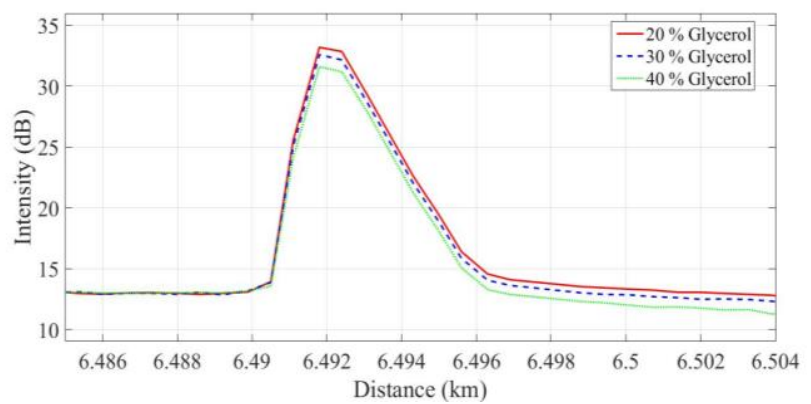

Fig.3. Enlarged view of the reflection from the sensor tip when the fiber is exposed to $20 \%, \% 30$, and $40 \%$ glycerol solutions

\section{ANALYSIS OF EXPERIMENTAL RESULTS}

Based on the measured reflection coefficient from the sensor tips, the refractive indices of the prepared solutions were calculated using Eq. (2) and (3). Table III and IV show $R_{\text {end }}$ values measured at different wavelengths (at $1550 \mathrm{~nm}$ and $1625 \mathrm{~nm}$ ), together with the calculated refractive indices using these $\mathrm{R}_{\text {end }}$ and $\mathrm{n}_{1}$ values.

The absence of highly sensitive test equipment (e.g. electronic micropipette) prevented the preparation of the solution at the pre-determined concentration values. To overcome this limitation, the actual amount of concentration of the prepared chemicals were determined using the RI values measured by RE50 digital refractometer of distilled water, pure glycerin and related chemical (Eq. (5)). These concentration amounts were then used to determine the refractive indices of the solutions at $1550 \mathrm{~nm}$. Conversion of the refractive indices of the chemicals at $589 \mathrm{~nm}$ to that of at $1550 \mathrm{~nm}$ was realized based on the refractive index values of distilled water and glycerin at $1550 \mathrm{~nm}$ given in the literature [15].

The real concentration values $\left(\mathrm{X}_{\text {real }}\right)$ of a glycerin-water solution at different wavelengths were obtained as:

$n_{x}(\lambda)=\frac{\left(n_{\text {pure_glycerin }}(\lambda) \times X_{\text {real }}\right)+\left(n_{\text {water }}(\lambda) \times\left(100-X_{\text {real }}\right)\right)}{100}(5)$

A numerical example for determining the exact concentration value of $70 \%$ glycerin solution for $589.3 \mathrm{~nm}$ : $\mathrm{n}_{\text {water }}=1.33300, \mathrm{n}_{\text {pure_glycerin }}=1.47332$ and $\mathrm{n}_{\mathrm{x}}=1.43612$ at $589.3 \mathrm{~nm}$. From Eq. (5) $\mathrm{X}_{\text {real }}$ was found to be $\mathrm{X}_{\text {real }}=73.489 \%$.

The refractive index value of $73.489 \%$ glycerine-water solution at $1550 \mathrm{~nm}$ was then calculated to be $\mathrm{n}_{\mathrm{x}}=1.419799 \approx$ 1.4198 using: $\mathrm{n}_{\text {water }}=1.3164$ and $\mathrm{n}_{\text {pure_glycerin }}=1.4571$ (at 1550 $\mathrm{nm})$.

TABLE III

EXPERIMENTAL RESULTS AND REFERENCE RI VALUES FOR GLYCEROL SOLUTIONS (SET-1)

\begin{tabular}{|c|c|c|c|c|c|}
\hline \multicolumn{2}{|c|}{ Concentrations } & \multicolumn{2}{|c|}{ Reference RIs } & \multirow{2}{*}{$\begin{array}{l}\mathbf{R}_{\text {end }} \\
(\mathbf{d B})\end{array}$} & \multirow{2}{*}{$\begin{array}{c}\text { Calculated RIs at } \\
\begin{array}{c}\lambda=1550 \mathrm{~nm} \\
\mathrm{n}_{1}=1.4473\end{array}\end{array}$} \\
\hline $\begin{array}{l}\text { Originally } \\
\text { aimed \% }\end{array}$ & Real \% & $\begin{array}{c}\mathbf{n}(\lambda) \\
\lambda=589.3 \\
\mathbf{n m}\end{array}$ & $\begin{array}{c}\mathbf{n}(\lambda) \\
\lambda=1550 \\
\mathbf{n m}\end{array}$ & & \\
\hline Air & - & 1.00027 & - & -16.35 & $1.0649 \pm 3.85 \times 10^{-3}$ \\
\hline Water & - & 1.33300 & 1.3164 & -27.70 & $1.3327 \pm 1.25 \times 10^{-3}$ \\
\hline 10 & 9.999 & 1.34703 & 1.3305 & -28.80 & $1.3459 \pm 1.10 \times 10^{-3}$ \\
\hline 20 & 23.425 & 1.36587 & 1.3494 & -30.80 & $1.3662 \pm 0.95 \times 10^{-3}$ \\
\hline 30 & 33.089 & 1.37943 & 1.3630 & -32.00 & $1.3764 \pm 0.80 \times 10^{-3}$ \\
\hline 40 & 43.052 & 1.39341 & 1.3770 & -34.00 & $1.3907 \pm 0.65 \times 10^{-3}$ \\
\hline 50 & 48.439 & 1.40097 & 1.3846 & - & - \\
\hline 60 & 63.626 & 1.42228 & 1.4059 & -38.40 & $1.4129 \pm 0.40 \times 10^{-3}$ \\
\hline 70 & 73.489 & 1.43612 & 1.4198 & -41.60 & $1.4234 \pm 0.30 \times 10^{-3}$ \\
\hline 75 & 78.328 & 1.44291 & 1.4266 & -43.80 & $1.4287 \pm 0.20 \times 10^{-3}$ \\
\hline 84 & 85.640 & 1.45317 & 1.4369 & -48.70 & $1.4367 \pm 0.10 \times 10^{-3}$ \\
\hline 86 & 86.959 & 1.45502 & 1.4388 & -49.40 & $1.4375 \pm 0.10 \times 10^{-3}$ \\
\hline 87 & 88.783 & 1.45758 & 1.4413 & -50.50 & $1.4387 \pm 0.10 \times 10^{-3}$ \\
\hline 88 & 90.287 & 1.45969 & 1.4434 & -52.00 & $1.4400 \pm 0.05 \times 10^{-3}$ \\
\hline 90 & 96.045 & 1.46777 & 1.4515 & -58.97 & $1.4506 \pm 0.05 \times 10^{-3}$ \\
\hline 100 & - & 1.47332 & 1.4571 & -52.23 & $1.4544 \pm 0.05 \times 10^{-3}$ \\
\hline
\end{tabular}


TABLE IV

EXPERIMENTAL RESULTS AND REFERENCE RI VALUES FOR GLYCEROL SOLUTIONS (SET-2)

\begin{tabular}{|c|c|c|c|c|}
\hline \multicolumn{2}{|c|}{ Concentrations } & \multirow{2}{*}{$\begin{array}{c}\mathbf{n}(\lambda) \\
\lambda=\mathbf{5 8 9 . 3} \\
\mathbf{n m}\end{array}$} & \multirow[b]{2}{*}{$\mathbf{R}_{\text {end }}(\mathbf{d B})$} & \multirow{2}{*}{$\begin{array}{c}\text { Calculated RIs at } \\
\lambda=1625 \mathrm{~nm}, \\
\mathrm{n}_{1}=1.4463\end{array}$} \\
\hline $\begin{array}{c}\text { Originally } \\
\text { aimed \% }\end{array}$ & Real \% & & & \\
\hline Air & - & 1.00027 & -16.40 & $1.0660 \pm 3.80 \times 10^{-3}$ \\
\hline Water & - & 1.33300 & -28.10 & $1.3368 \pm 1.20 \times 10^{-3}$ \\
\hline 10 & 9.999 & 1.34703 & -28.50 & $1.3415 \pm 1.15 \times 10^{-3}$ \\
\hline 20 & 23.425 & 1.36587 & -29.70 & $1.3546 \pm 1.00 \times 10^{-3}$ \\
\hline 30 & 33.089 & 1.37943 & -31.00 & $1.3670 \pm 0.90 \times 10^{-3}$ \\
\hline 40 & 43.052 & 1.39341 & -32.70 & $1.3808 \pm 0.75 \times 10^{-3}$ \\
\hline 50 & 48.439 & 1.40097 & -34.30 & $1.3916 \pm 0.60 \times 10^{-3}$ \\
\hline 60 & 63.626 & 1.42228 & -38.40 & $1.4119 \pm 0.40 \times 10^{-3}$ \\
\hline 70 & 73.489 & 1.43612 & - & - \\
\hline 75 & 78.328 & 1.44291 & -43.90 & $1.4280 \pm 0.25 \times 10^{-3}$ \\
\hline 84 & 85.640 & 1.45317 & -51.45 & $1.4386 \pm 0.10 \times 10^{-3}$ \\
\hline 86 & 86.959 & 1.45502 & - & - \\
\hline 87 & 88.783 & 1.45758 & -54.10 & $1.4406 \pm 0.10 \times 10^{-3}$ \\
\hline 88 & 90.287 & 1.45969 & -57.75 & $1.4426 \pm 0.05 \times 10^{-3}$ \\
\hline 90 & 96.045 & 1.46777 & -59.85 & $1.4492 \pm 0.05 \times 10^{-3}$ \\
\hline 100 & - & 1.47332 & -54.84 & $1.4515 \pm 0.05 \times 10^{-3}$ \\
\hline
\end{tabular}

In the Table III and IV calculated RIs were given by adding the OTDR's precision $( \pm 0.1 \mathrm{~dB})$. A systematic difference between the measured and the theoretical $R_{\text {end }}$ values was observed. This difference can be attributed to the OTDR's optical return loss (ORL) measurement accuracy, which is \pm 1 dB.

The RI values obtained by using the proposed method versus reference refractive index values calculated for $1550 \mathrm{~nm}$ (for experimental Set-1 at $1550 \mathrm{~nm}$ ) are represented in Fig. 4. The slope of the linear fit is: 0.83901 . The fitting function is $\mathrm{n}=$ $0.83901 \times R E F+0.23157$, with a fitting degree of $R^{2}=0.9973$, norm of residuals $=0.0074$. The corrected version based on the OTDR's ORL accuracy was plotted on a new graph (Fig. 5 ) and the slope closer to 1 was obtained. The slope of the linear fit is: 0.93735 . The fitting function on this new graph was obtained as $\mathrm{n}=0.93735 \times \mathrm{REF}+0.089037$, having a fitting degree of $\mathrm{R}^{2}=0.9975$, and norm of residuals $=0.0081$.

It was observed that the refractive index differences occurred between the reference and the calculated values decreased as the refractive index of the external medium becomes closer to the effective refractive index value of the core (cf. Table III and IV).

The refractive index of the materials depends on the wavelength of the light source used for the measurement, as well as on the temperature.

For most of the liquids, the temperature dependence of the refractive index $(\partial \mathrm{n} /(\partial \mathrm{T}))$ is $10^{-4 \circ} \mathrm{C}^{-1}[16]$. The temperature variation of the laboratory was maximum $1-2^{\circ} \mathrm{C}$ during the whole experiments, therefore the influence of temperature could be ignored for measurements.

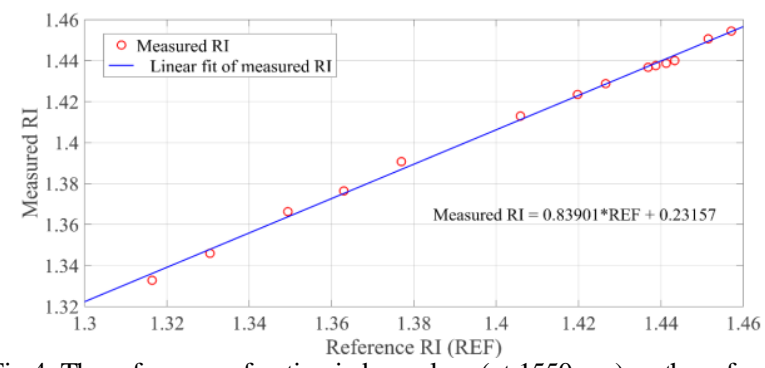

Fig.4. The reference refractive index values (at $1550 \mathrm{~nm}$ ) vs the refractive index values (at $1550 \mathrm{~nm}$ ) calculated using the proposed method

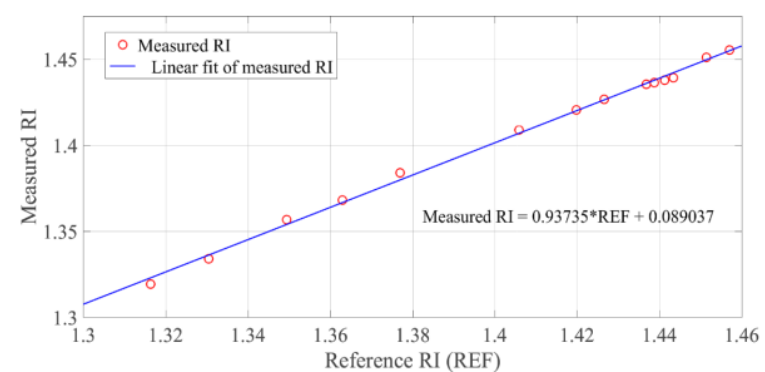

Fig.5. The reference refractive index values (at $1550 \mathrm{~nm}$ ) vs the refractive index values (at $1550 \mathrm{~nm}$ ) calculated using the corrected $\mathrm{R}_{\text {end }}$ values

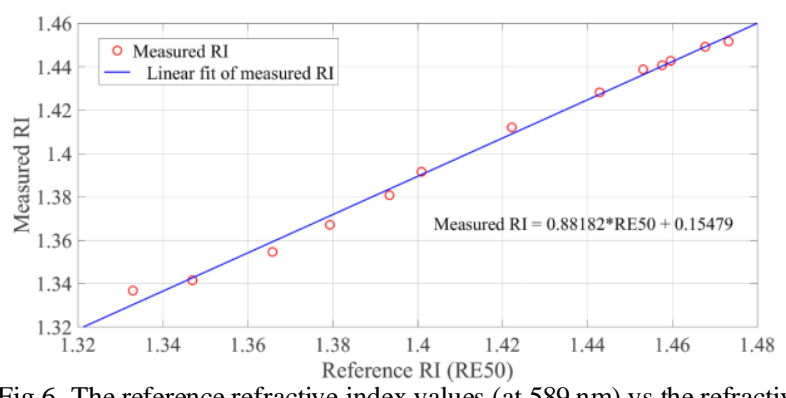

Fig.6. The reference refractive index values (at $589 \mathrm{~nm}$ ) vs the refractive index values (at $1625 \mathrm{~nm}$ ) calculated using the proposed method 


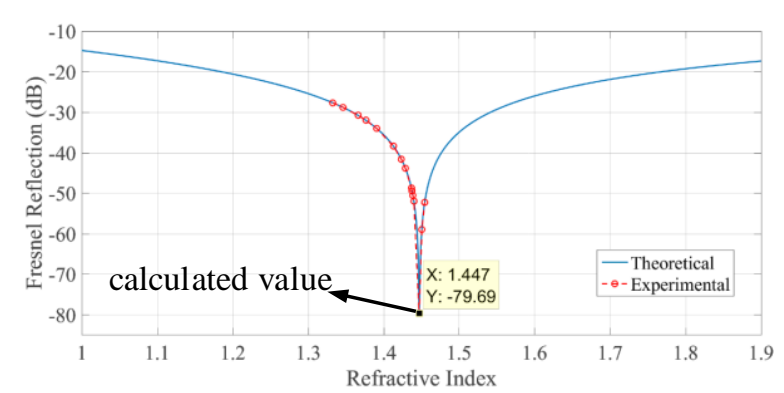

Fig.7. Experimental results and the theoretical curve fitting

Fig. 7 shows the experimental results (at $\lambda=1550 \mathrm{~nm}$ ) and the theoretical curve fitting these experimental points in the same graph.

The experimental results obtained for various chemicals such as ethanol, methanol, acetone and iso-propanol are presented in Table V. The differences between the values were in the second digit after the decimal point. The measurements were repeated three times to determine the measurement precision. The repeated measurements for acetone is listed in Table VI, where the standard deviation (precision) was obtained as $4.7 \times 10^{-4}$.

TABLE V

EXPERIMENTAL RESULTS AND REFERENCE RI VALUES FOR VARIOUS CHEMICALS

\begin{tabular}{|c|c|c|c|c|}
\hline \multirow[t]{2}{*}{ Chemical } & \multicolumn{2}{|c|}{$\begin{array}{c}\text { Reference RIs } \\
(\mathbf{n}(\lambda))\end{array}$} & \multirow{2}{*}{$\begin{array}{c}\text { Experimental } \\
\text { RIs At } 1550 \\
\text { nm }\end{array}$} & \multirow[b]{2}{*}{$\Delta \mathbf{n}$} \\
\hline & $\begin{array}{c}\text { At } 589 \\
\text { nm }\end{array}$ & $\begin{array}{c}\text { At } 1550 \\
\text { nm }\end{array}$ & & \\
\hline 2-propanol & 1.3772 & 1.3661 & $\begin{array}{c}1.3756 \pm 0.80 \times \\
10^{-3}\end{array}$ & $0.95 \times 10^{-2}$ \\
\hline Ethanol & 1.3614 & 1.3522 & $\begin{array}{c}1.3624 \pm 0.95 \times \\
10^{-3}\end{array}$ & $1.02 \times 10^{-2}$ \\
\hline Acetone & 1.3586 & 1.3483 & $\begin{array}{c}1.3605 \pm 0.95 \times \\
10^{-3}\end{array}$ & $1.22 \times 10^{-2}$ \\
\hline Methanol & 1.3284 & 1.3174 & $\begin{array}{c}1.3556 \pm 1.05 \mathrm{x} \\
10^{-3}\end{array}$ & $3.82 \times 10^{-2}$ \\
\hline
\end{tabular}

TABLE VI

DETERMINATION OF SENSOR PRECISION

\begin{tabular}{|c|c|c|c|}
\hline $\begin{array}{c}\text { Number of } \\
\text { measurement }\end{array}$ & $\begin{array}{c}\mathbf{R}_{\text {end }} \\
(\mathbf{d B})\end{array}$ & $\mathbf{n}_{\mathbf{1}}=\mathbf{1 . 4 4 6 3}$ & $\begin{array}{c}\text { Deviation of } \\
\text { each point }\end{array}$ \\
\hline $\mathbf{1}$ & -29.9 & 1.3566 & 0.0003 \\
\hline $\mathbf{2}$ & -29.9 & 1.3566 & 0.0003 \\
\hline $\mathbf{3}$ & -29.8 & 1.3556 & 0.0007 \\
\hline
\end{tabular}

\section{DISCUSSION \& CONCLUSION}

Requirements for quality standards in different areas, and increased public awareness have created a need for more reliable, faster, automated, remote and/or portable refractive index sensors and monitoring systems with multimeasurement capability. Fiber-based RI sensors provides attractive solutions in this area.

The measurement of refractive indices of common solvents in the range of telecommunication wavelengths is becoming critical due to the growing interest in fiber optic sensing at telecommunication wavelength range [17].

The aim of this work is to meet the calibration requirements of RI sensors that operate in the infrared wavelength range.
We provided a straightforward solution to this requirement using a conventional tool (OTDR) as the sensor interrogation unit.

Indeed, the wavelength range implemented in most of the fiber-based sensors and applications is within the classical telecommunication wavelength region as the commercial opto-electronic devices are readily available with reasonable prices. OTDR is one of them. On the current marketplace, one can easily find out a hand-held OTDR emitting at two wavelengths at reasonable prices. This opportunity is largely due to the emerging deployment (and related testing requirements) of optical fibre, particularly in the broadband access networks (e.g. NG-PONs). Hence, the proposed method based on OTDR provides cheap and easy RI measurement capability eliminating all expensive devices (lock-in amplifier, fast pulse modulation of laser source, fast detectors, $\mathrm{GHz}$ oscilloscopes...) and custom fibers (photonic crystal, microfiber, plastic optical fibers, SPR) reported in the previous literature.

The refractive index sensor investigated in this study is based on Fresnel reflection which uses SMF fiber tip as sensing point interrogated by an OTDR (operating at two different telecom wavelengths) from a distant location. Experimental work realized on different concentrations of glucose-water and glycerol-water solutions successfully demonstrated the capability of the proposed sensor in measuring RI of liquid chemicals with a precision of $4.7 \times 10^{-4}$. We provided substantial amount of measurements of refractive indices of common solvents and solutions at both $1550 \mathrm{~nm}$ and $1625 \mathrm{~nm}$ using a systematical and comparative approach.

Compatibility of the proposed sensor with the classical telecommunication wavelength range test equipment is the key advantage. Processing method used in the experiments (in calculating real concentration values of the solutions and determination of effective refractive index of the sensor tip) would serve as a reference for future investigations in this domain.

A wide panel of applications can be envisaged for the proposed sensor system, particularly those in difficult environments, requiring the self-calibration, easy implementation, multi-point, and remote measurement features.

\section{ACKNOWLEDGMENT}

The paper was supported by the Izmir Institute of Technology (IZTECH) under the Scientific Research Project (BAP-2016IYTE-50). The authors would like to thank Dr. Burcu Okuklu (IYTE Food Engineering Department) for reference RI measurements using conventional refractometer.

\section{REFERENCES}

[1] J. Oelhafen, T. Mayr, F. Dorner, K. Moutzouris, J. Roths, K. Drechsler, "Fiber Optic Measurement System for Fresnel Reflection Sensing: Calibration, Uncertainty, and Exemplary Application in TemperatureModulated Isothermal Polymer Curing", Journal of Lightwave Technology, Vol.36, No.4, February 2018, pp.939 - 945.

[2] G. An, X. Hao, S. Li, X. Yan, X. Zhang, "D-shaped photonic crystal fiber refractive index sensor based on surface plasmon resonance", Applied Optics, Vol.56, No.24, 2017, pp.6988-6992. 
[3] I.D. Villar, J.L. Cruz, A.B. Socorro, S. Diaz, J.M. Corres, F.J. Arregui, I.R. Matias, "Monitoring the Etching Process in LPFGs towards Development of Highly Sensitive Sensors", Proceedings, Vol.1, No.4, 2017, pp.331-334.

[4] K. Yüksel, "Optical fiber sensor system for remote and multi-point refractive index measurement", Sensors and Actuators A: Physical, Vol.250, 2016, pp.29-34.

[5] R. C. Weast, S. M. Selby (ed), Handbook of Chemistry and Physics, (48 ${ }^{\text {th }}$ edition), CRC Handbook of Chemistry and Physics Press, 1968.

[6] C.-B. Kim, C.-B. Su, "Measurement of the refractive index of liquids at 1.3 and 1.5 micron using a fibre optic Fresnel ratio meter", Measurement Science and Technology, Vol.15, No.9, 2004, pp.16831686.

[7] A. Basgumus, F.E. Durak, A. Altuncu, G. Yilmaz, "A universal and stable all-fiber refractive index sensor system", IEEE Photonics Technology Letters, Vol.28, No.2, 2015, pp.171-174.

[8] W. Xu, X.G. Huang, J.S. Pan, "Simple fiber-optic refractive index sensor based on Fresnel reflection and optical switch", IEEE Sensors Journal, Vol.13, No.5, 2013, pp.1571-1574.

[9] C.-L. Zhao, J. Li, S. Zhang, Z. Zhang, S. Jin, "Simple Fresnel reflection-based optical fiber sensor for multipoint refractive index measurement using an AWG", Photonics Technology Letters, Vol.25, No.6, 2013, pp.606-608.

[10] R. Selvas-Aguilar, A. Castillo-Guzman, L. Cortez-Gonzalez, et al., "Noncontact Optical Fiber Sensor for Measuring the Refractive Index of Liquids" Journal of Sensors, Vol.2016, Article ID 3475782, 2016, 6 pages.

[11] C.-H. Yeh, C.-W. Chow, J.-Y. Sung, P.-C. Wu, W.-T. Whang, F.-G. Tseng, "Measurement of organic chemical refractive indexes using an optical time-domain reflectometer", Sensors, Vol.12, No.1, 2012, pp.481-488.

[12] J.-Y. Yuan, C.-L. Zhao, M. Ye, J. Kang, Z. Zhang, S.-Z. Jin. "A Fresnel reflection-based optical fiber sensor system for remote refractive index measurement using OTDR", Photonic Sensors, Vol.4, No.1, March 2014, pp. 48-52.

[13] O.V. Butov, K.M. Golant, A.L. Tomashuk, M.J.N. van Stralen, A.H.E. Breuls, "Refractive index dispersion of doped silica for fiber optics", Optics Communications, Vol.213, 2002, pp.301-308.

[14] Y. Kang, Calculations and Measurements of Raman Gain Coefficients of Different Fiber Types, MSc Thesis, Virginia Polytechnic Institute and State University, 2002.

[15] J.E. Saunders, C. Sanders, H. Chen, H.-P. Loock, "Refractive indices of common solvents and solutions at $1550 \mathrm{~nm}$ ", Applied Optics, Vol.55, No.4, 2016, pp.947-953.

[16] J.-H. Chen, X.-G. Huang, W.-X. He, J. Tao, "A parallel-multipoint fiber-optic temperature sensor based on Fresnel reflection", Optics \& Laser Technology, Vol.43, No.8, 2011, pp.1424-1427.

[17] H. Apriyanto, G. Ravet, O.D. Bernal, M. Cattoen, H.C. Seat, V. Chavagnac, F. Surre, J.H. Sharp, "Comprehensive Modeling of Multimode Fiber Sensors for Refractive Index Measurement and Experimental Validation”, Scientific Reports, Vol.8, Article number: $5912,2018$.

\section{BIOGRAPHIES}

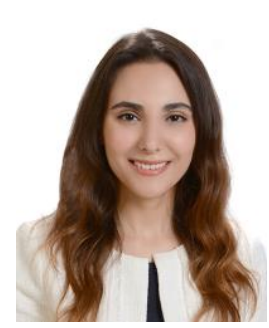

CANSU IDE. She received the B.S. degree in physics engineering from Hacettepe University, in 2011 and M.S. degree in electrical - electronics engineering from Izmir Institute of Technology University, in 2017.

From 2014 up to date, she has been a research and development engineer at Ermaksan Optoelectronics R\&D Center. Her research interests include fiber optic sensors, optical fiber gratings, structural health monitoring, high power fiber lasers and laser diodes.

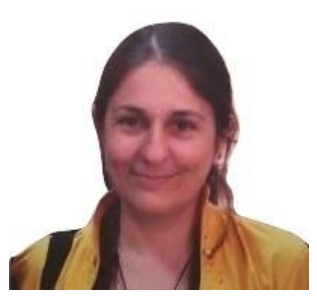

KIVILCIM YÜKSEL ALDOĞAN received the M.S. degrees in electronics engineering from the Ege University, in 2000 and the Ph.D. degree in applied sciences from Mons Engineering Faculty, Mons, Belgium, in 2011. Between 2002 and 2005, she worked at Multitel asbl (Belgium), Applied Photonics Department, as an optical research engineer.

Afterwards, she worked as a research assistant at University of Mons (UMONS, Belgium) until 2012.

From 2012 up to date, she has been an Assistant Professor at the İzmir Institute of Technology. Her research interests include Rayleigh-based reflectometry techniques and their applications to fiber optic sensors, fiber Bragg grating sensors, monitoring of optical access networks, and development of innovative traffic monitoring solutions. 